\title{
Identifying acute malnutrition - do we have an answer for policy makers?
}

Rosan Meyer ${ }^{1 *}$ and Luise Marino ${ }^{2}$

\begin{abstract}
It is thought that 178 million children are underweight worldwide, and 20 million suffer from severe acute malnutrition each year, which carries a higher mortality. Growth parameters below a nominal cut-off indicate acute or chronic malnutrition, which are used as indicators for commencing therapeutic nutritional intervention in individuals and populations.

The World Health Organization and United Nation Children Fund recommend the use of a cut-off for weight-for-height of below -2 standard deviations and -3 standard deviations for moderate and severe malnutrition respectively. In conjunction with weight-for-height the World Health Organization also suggests the use of mid upper arm circumference using a cut-off point of $<115 \mathrm{~mm}$ to define severe malnutrition and $<125 \mathrm{~mm}$ for moderate malnutrition. As these parameters influence the level of nutritional support provided to children in need it is important to ensure that the right measures are used to identify those that require nutritional support. There has been debate around using only mid-upper-arm- circumference for the identification of children with malnutrition, as studies indicated this measure to be an easy, reliable method with good sensitivity and specificity, however concern has been raised whether arm circumference alone is a reliable marker to identify children with malnutrition. As recently reported in BMC Nutrition, Grellety \& Golden performed a study to assess the relationship between the two measures, particularly with respect to regional and body differences between populations and the subsequent implications for the accurate identification of malnutrition. This study found significant differences in the populations identified with malnutrition using either method. As such a recommendation was made by the authors to continue to use both mid-upper-arm-circumference and weight-for-height, as they complement each other and better account for country and population differences when used together.
\end{abstract}

Keywords: Malnutrition, Mid-upper-arm-circumference, Weight-for-height, Therapeutic nutrition program

\section{Background}

Anthropometric parameters form the backbone of nutritional assessment in paediatrics. Growth parameters below a nominal cut-off indicate acute or chronic malnutrition, which increases the risk of mortality [1], and are used as indicators for commencing therapeutic nutritional intervention in individuals and populations $[2,3]$. Worldwide, it is thought that 178 million children are underweight, and 20 million suffer from severe acute malnutrition each year, which carries a higher mortality [4]. Children receiving therapeutic nutritional input for the management of malnutrition have been shown to have faster recovery than those without and therefor the

\footnotetext{
* Correspondence: r.meyer@imperial.ac.uk

'Department Paediatric Imperial College, London, UK

Full list of author information is available at the end of the article
}

point at which these should be implemented and the duration of nutrition support is important for policy makers $[3,5]$. In addition, the sensitivity and specificity of measures and their cut-offs also impact on the funding required to address malnutrition [1]. In 2008 it was estimated that 250-300 million US\$ was invested in basic nutrition support between 2000-2004 and in 2009 Medecin Sans Frontier estimated the average annual amount spent at 350 million US\$, whereas the World Bank puts an annual requirement of 12.5 billion US\$ to address malnutrition world-wide $[4,6]$. In the light of both the human and financial cost, it is therefore important that consensus is reached on how to best identify those children at need of nutrition support using sensitive and specific anthropometric cut off points for programme entry and exit criteria. 


\section{Considerations for using weight-for-height and/or mid upper arm circumference}

The World Health Organization (WHO) and United Nation Children Fund (UNICEF) recommend the use of a cut-off for weight-for-height (WTH) of below -2 standard deviations (SD) and - 3 SD for moderate and severe malnutrition respectively [7]. Data has shown that children with a WTH below -3 SD based on the WHO standards have a 9-fold increased risk of mortality than children with a WTH above -1 SD. In addition WHO standards also recommend the use of mid upper arm circumference (MUAC)-for-age, using a cut-off point of $<115 \mathrm{~mm}$ to define severe malnutrition and $<125 \mathrm{~mm}$ for moderate malnutrition. Similarly to WTH, research indicates an increased risk of death with a MUAC less than $115 \mathrm{~mm}[2,7]$. Numerous studies have found MUAC to be an easy, reliable method with good sensitivity and specificity $[8,9]$. Although the prevalence using either WTH or MUAC as cut-off for malnutrition were very similar at $3.22 \%$ and $3.27 \%$, crucially only $40 \%$ selected by one criterion was also selected by the other. This in part has been explained by the fact that a low MUAC tends to be more prevalent in younger children due to the set cut-off value of $115-125 \mathrm{~mm}$, whereas WTH is not a static measure and adjusts according to age. As such to date it has been recommended to use both parameters, however following the publication by Goossens et al. [10] indicating MUAC a useful and easy alternative to using WTH for feeding programs, some organizations have started to move to a MUAC only cut offs to guide entry criteria for therapeutic nutritional programmes. Although MUAC would provide an easy, reproducible measure that is simpler to use in resource poor countries, many questions in regard to the differences in populations/countries and the relationship to weight-for-height remain outstanding.

\section{Study findings and implication}

As recently reported in BMC Nutrition, the study by Grellety \& Golden recognises these outstanding questions and in particular the implications for future nutritional programs [11]. As such the authors performed a study to assess the relationship between the two measures, particularly in respect to regional and body differences between populations (i.e. East African vs. South East Asia) and the subsequent implications for the accurate identification of malnutrition. They included 1832 surveys, with $1,404,995$ children with plausible data, from 47 countries between 1986-2014, that included WTH and MUAC as recommended by the WHO. Overall $16.3 \%$ were identified with Global Acute Malnutrition (GAM) by either MUAC or WTH and $3.5 \%$ as Severe Acute Malnutrition (SAM) also using either of these measures. Importantly this study found that that the degree of overlap between the 2 indicators for GAM and SAM were consistently low at $29.9 \% \pm 15.3 \%$ and $16 \% \pm 5.4 \%$ respectively. This study also found dramatic differences in the percentage of children classified with either GAM or SAM using either criterion. For GAM in 11 countries more than $75 \%$ of malnourished children would be identified using MUAC as only criteria, but in 9 countries this drops to less than $25 \%$ if only this parameter was used. When the authors assessed the data for the identification of SAM, even more differences were apparent: MUAC would not identify more than $75 \%$ of SAM children in any analysed country, in which more than 75 SAM children were identified. The analysis by country found that if MUAC alone was used to identify GAM and SAM, in only $57 \% \pm 18 \%$ and $55 \% \pm 19$ of malnourished children would be identified respectively. If only WTH was used then only $70 \% \pm 15 \%$ of children with GAM would be identified and only $61 \% \pm 18 \%$ for SAM [11].

This study [11] has limitations that have been recognised by the authors, which include the survey data that is dominated by patient data from Africa and the heterogeneity of data generated by certain countries. Nevertheless, the publication contributes significantly to the question for policy makers and programme funders as whether to use both MUAC and WTH or just MUAC as indicators of malnutrition. Although to our knowledge this is the first study using such a large patient database and rigorous statistical methods to answer this question, other studies have highlighted concerns regarding using MUAC as only criterion for therapeutic feeding. Grellety et al. [12] published a study from Sudan indicating that MUAC only identified more severely malnourished children with a higher risk of mortality but failed to identify a third of the children who died. A study by Isanaka et al. [13] investigated differences in children identified for therapeutic feeding by MUAC and/or WHT in terms of demographic, anthropometric, clinical, and laboratory and treatment response characteristics and found that using MUAC only identified younger and more female children but did not well differentiate children in terms of other measures of nutritional vulnerability. There are also clear population differences, highlighted by Dasgupta et al. [14] in their study when using either MUAC and WHT in India. The stunting levels in India are higher than in Africa and that study found that $26 \%$ of the children who had a WTH $\leq-3$ were severely stunted compared to $60.9 \%$ of children with a MUAC $\leq 115 \mathrm{~mm}$.

\section{Conclusion}

This study [11] provides important evidence to indicate that MUAC is not superior to WTH in the assessment of malnutrition in children requiring therapeutic feeding. It supports concerns highlighted by other authors that using MUAC as single parameter may lead to a significant 
number of vulnerable children not being identified with malnutrition. As such, Grellety \& Golden provide robust data that both these measures should be used when identifying children GAM/SAM as they complement each other and better account for country and population differences if used together.

\section{Abbreviations}

GAM: Global acute malnutrition; MUAC: Mid-upper-arm-circumference; SAM: Severe acute malnutrition; SD: Standard deviation; UNICEF: United Nation Children Fund; WTH: Weight-for-height; WHO: World Health Organisation.

\section{Competing interests}

Neither authors have any competing interest pertaining this publication.

\section{Authors' contributions}

RM wrote publication. LM reviewed and corrected publication. Both authors have approved the publication.

\section{Author details}

${ }^{1}$ Department Paediatric Imperial College, London, UK. ${ }^{2}$ Department of Nutrition and Dietetics, University Hospital Southampton NHS Trust, Southampton, UK.

Received: 10 February 2016 Accepted: 23 March 2016

Published online: 04 April 2016

\section{References}

1. Pelletier DL, Frongillo EA. Changes in child survival are strongly associated with changes in malnutrition in developing countries. J Nutr. 2003;133(1):107-19.

2. World Food Program, The UN Regugee Agency. Guidelines for Selective Feeding: The Management of Malnutrition in Emergencies. United Nations Refugee Agency 2011 January [cited 2016 Jan 2]; Available from: URL: http://www.unhcr.org/4b7421fd20.html. Accessed 4 Jan 2016.

3. Defourny I, Minetti A, Harczi G, Doyon S, Shepherd S, Tectonidis M, et al. A large-scale distribution of milk-based fortified spreads: evidence for a new approach in regions with high burden of acute malnutrition. PLoS One. 2009:4(5), e5455.

4. Morris SS, Cogill B, Uauy R. Effective international action against undernutrition: why has it proven so difficult and what can be done to accelerate progress? Lancet. 2008;371(9612):608-21.

5. Trehan I, Banerjee S, Murray E, Ryan KN, Thakwalakwa C, Maleta KM, et al. Extending supplementary feeding for children younger than 5 years with moderate acute malnutrition leads to lower relapse rates. J Pediatr Gastroenterol Nutr. 2015;60(4):544-9.

6. Malnutrition:how much is being spent ? An analysis of nutrition funding flows 2004-2007. Switzerland: http://www.msfaccess.org/content/malnutritionhow-much-being-spent-analysis-nutrition-funding-flows-2004-2007. Accessed 25 Mar 2015

7. World Health Organization, UNICEF. WHO child growth standards and the identification of severe actue malnutrition in infants and children. Geneva: WHO; 2009. Report No.: WS103.

8. Dale NM, Myatt M, Prudhon C, Briend A. Using mid-upper arm circumference to end treatment of severe acute malnutrition leads to higher weight gains in the most malnourished children. PLoS One. 2013:8(2), e55404.

9. Mogendi JB, De SH, Gellynck X, Saeed HA, Makokha A. Efficacy of mid-upper arm circumference in identification, follow-up and discharge of malnourished children during nutrition rehabilitation. Nutr Res Pract. 2015;9(3):268-77.

10. Goossens S, Bekele Y, Yun O, Harczi G, Ouannes M, Shepherd S. Mid-upper arm circumference based nutrition programming: evidence for a new approach in regions with high burden of acute malnutrition. PLoS One. 2012;7(11), e49320
11. Grellety E \& Golden MH. Weight-for-height and mid-upper-arm circumference should be used independently to diagnose acute malnutrition: policy implications. BMC Nutr. 2016;2(10) DOI 10.1186/s40795-016-0049-7.

12. Grellety E, Krause LK, Shams EM, Porten K, Isanaka S. Comparison of weight-for-height and mid-upper arm circumference (MUAC) in a therapeutic feeding programme in South Sudan: is MUAC alone a sufficient criterion for admission of children at high risk of mortality? Public Health Nutr. 2015;18(14):2575-81.

13. Isanaka S, Guesdon B, Labar AS, Hanson K, Langendorf C, Grais RF. Comparison of Clinical Characteristics and Treatment Outcomes of Children Selected for Treatment of Severe Acute Malnutrition Using Mid Upper Arm Circumference and/or Weight-for-Height Z-Score. PLoS One. 2015;10(9), e0137606

14. Dasgupta R, Sinha D, Jain SK, Prasad V. Screening for SAM in the community: is MUAC a simple tool? Indian Pediatr. 2013:50(1):154-5.

\section{Submit your next manuscript to BioMed Central} and we will help you at every step:

- We accept pre-submission inquiries

- Our selector tool helps you to find the most relevant journal

- We provide round the clock customer support

- Convenient online submission

- Thorough peer review

- Inclusion in PubMed and all major indexing services

- Maximum visibility for your research

Submit your manuscript at www.biomedcentral.com/submit 